\title{
Ocular alignment and refraction in preterm children at I and 6 years old
}

This article was published in the following Dove Press journal:

Clinical Ophthalmology

2 July 2014

Number of times this article has been viewed

\author{
Muna Al Oum' \\ Simone Donati' \\ Luigi Cerri' \\ Massimo Agosti ${ }^{2}$ \\ Claudio Azzolini'
}

'Department of Surgical and Morphological Sciences, Section of Ophthalmology, School of Medicine, University of Insubria, Varese, Italy;

${ }^{2}$ Neonatology Unit, Ospedale Filippo

Del Ponte, Varese, Italy
Correspondence: Claudio Azzolini Department of Surgical and Morphological Sciences, Section of Ophthalmology, School of Medicine, University of Insubria-Circolo Hospital, Via Guicciardini 9, 21 I00,

Varese, Italy

Tel +39332278217

Fax +39332278310

Email claudio.azzolini@uninsubria.it
Purpose: To investigate cycloplegic refraction and ocular alignment in a population of preterm children at 1 and 6 years old.

Patients and methods: We included 261 preterm infants with a birth weight $\leq 1,500 \mathrm{~g}$ and a gestational age $\leq 32$ weeks; there were 217 preterm infants (group 1), 28 preterm infants with mild retinopathy of prematurity (ROP) (group 2), and 16 preterm infants affected by severe ROP (group 3). Each patient underwent retinoscopy, ocular alignment assessment, and fundus examination at 1 and 6 years old.

Results: The prevalence of refractive errors and ocular alignment abnormalities at 1 year old in groups 2 and 3 compared to group 1 were, respectively $(P<0.05)$ : myopia $18 \%$ and $40.6 \%$ versus $6.9 \%$; hyperopia $28.6 \%$ and $22 \%$ versus $39.2 \%$; astigmatism $53.4 \%$ and $37.4 \%$ versus $53.9 \%$; and strabismus $12.5 \%$ and $38 \%$ versus $5.3 \%$. At 6 years old, they were, respectively $(P<0.05)$ : myopia $10.8 \%$ and $28.4 \%$ versus $7.4 \%$; hyperopia $48.3 \%$ and $40.5 \%$ versus $62 \%$; astigmatism $40.9 \%$ and $31.1 \%$ versus $30.6 \%$; and strabismus $25 \%$ and $56.25 \%$ versus $11.5 \%$. Conclusion: At 6 years old, we observed increased rates of both hyperopia and strabismus in all groups compared to 1-year-old children. In preterm children with mild and severe ROP, we recorded increased rates of myopia and strabismus versus preterm children without ROP, and the risk of developing these disorders increased significantly with ROP severity. Astigmatism at 1 year old is not predictive of further development during growth. Patients born prematurely should be informed of the possible risks of ocular alterations due to refractive and ocular component changes.

Keywords: refraction strabismus, retinopathy of prematurity, vision screening, visual impairment

\section{Introduction}

Neonatal care has increased the survival rates of extremely preterm infants with birth weights $(B W) \leq 1,000$ g, or a gestational age $(\mathrm{GA}) \leq 28$ weeks; at the same time retinopathy of prematurity (ROP) has become a major threat to visual function. ${ }^{1-3}$

ROP is the most widely recognized cause of visual impairment following preterm birth, and it is defined as a vision-threatening disease. ${ }^{4}$ ROP is responsible for up to $15 \%$ of all causes of blindness in Western countries, and up to $60 \%$ in developing countries. ${ }^{4}$ A number of risk factors are implicated in the development of ROP, the most widely recognized of which is the degree of immaturity measured by BW and GA, together with prolonged exposure to supplementary oxygen. ${ }^{1-3}$ ROP is a biphasic disease that has an initial phase of retinal vessel growth retardation (from birth to 30-32 weeks), and a second phase of vessel proliferation (around 32-34 weeks postmenstrual age). ${ }^{5,6}$ Serious retinopathy until tractional retinal detachment occurs in $10 \%-15 \%$ of infants with a BW of $<1,200 \mathrm{~g}$. Children with ROP are known to develop refractive errors ${ }^{7}$ such as myopia, hyperopia, astigmatism, anisometropia, and other alterations in ocular alignment. ${ }^{8,9}$ 
Few studies in the literature have reported the prevalence of refractive errors and strabismus in preterm infants at different stages of growth. ${ }^{10,11}$ In particular, several authors described the impact of myopia and its association with prematurity. ${ }^{12,13}$ Myopia of prematurity (MOP) is one of these features, and it is represented by the arrested development of the anterior segment, irrespective of ROP, which is different from physiological myopia and myopia secondary to severe ROP. ${ }^{14,15}$

The aim of the present study was to define a long-term evaluation of cycloplegic refraction errors and ocular alignment abnormalities in a population of preterm children with and without ROP at 1 year and 6 years of age, resulting from the close collaboration of our Department of Surgical and Morphological Sciences (University of Insubria, Varese, Italy) and Neonatology Unit (Ospedale Filippo Del Ponte, Varese, Italy).

\section{Patients and methods}

In this observational retrospective study, we examined all preterm infants born between January 1, 1997 and December 31, 2005 at our Neonatology Unit. We considered all infants with a BW of $\leq 1,500 \mathrm{~g}$ and a GA of $\leq 32$ weeks as preterm.

A total of 261 consecutive preterm patients were enrolled. Exclusion criteria were the presence of congenital cataract or corneal opacities, severe ocular or systemic malformations precluding refractive examination or ocular alignment evaluation, patients having undergone ocular surgery for severe ROP, and patients without complete medical records. Infants with mild or severe ROP, and those treated with laser therapy or cryotherapy according to standard clinical protocols, were included in the study. Informed consent was obtained from the parents of the study participants. The study conformed to the tenets of the Declaration of Helsinki.

Patients were subdivided into one of three groups. In presence of ROP, we defined stages 1 and 2 as "mild" ROP, and stages 3, 3 plus, 4, and 5 as "severe" ROP. Visual refraction, ocular alignment, and fundus examination were documented on clinical files for all included patients at 12 months and 72 months from birth, and these were inserted into our informatics database. With respect to visit scheduling, we considered acceptable an interval of \pm 45 days for the visit at month 12 and of \pm 3 months for the visit at the year 6 .

Visual refraction was assessed by retinoscopy. Cycloplegic refraction was measured after three instillations of $1 \%$ cyclopentolate eye drops at 10-minute intervals before the examination. Spherical refraction, cylindrical power, and astigmatic axis were assessed for each eye. Refractive errors were defined as the mean spherical equivalent (MSE):

$$
\mathrm{MSE}=\text { sphere }+1 / 2 \text { cylinder }
$$

Myopia was divided into three categories according to diopter (absolute value): $\leq 3 \mathrm{D} ;>3$ and $\leq 6 \mathrm{D} ;>6 \mathrm{D}$. Hyperopia was divided into two groups: $\leq 3 \mathrm{D}$ and $>3 \mathrm{D}$. Astigmatism was divided into two groups (absolute value): $\leq 1.5 \mathrm{D}$ and $>1.5 \mathrm{D}$. We defined refractive anisometropia as a difference between both eyes that was $>1.5 \mathrm{D}$.

The ocular alignment of preterm children was studied using the cover test. We defined heterophoria as deviations that were kept latent by a fusion mechanism, and heterotropia was regarded as deviations not kept in check by fusion; these were measured using the prism and/or cover test, as well as the Krimsky prism reflex test. ${ }^{16}$ Hence, we only considered heterotropia as a clinically significant ocular deviation (strabismus); we evaluated and reported the presence of heterophorias only as functional defect; it was not significant with respect to the data collected.

The presence of nystagmus was recorded and ocular movements were assessed to detect abnormalities. Binocular function was evaluated with the Lang Stereotest $1 .{ }^{17}$

The fundus examination was performed using indirect ophthalmoscopy with a Schepens ophthalmoscope (HEINE OMEGA $200^{\circledR}$; HEINE Optotechnik, Herrsching, Germany). Fundus characteristics and any ROP-related structural sequelae in children were described as normal findings (in the absence of pathological features) or as pathological findings in presence of vessel tortuosity, disc pallor, macular distortion or dragging, macular folds, tractional retinal detachment, and as a result of laser therapy or cryotherapy.

Cycloplegic refraction and ocular alignment were compared in patients without ROP to those with mild and severe ROP at 1 and 6 years of age to evaluate significant changes. A computerized database was established to facilitate data management and statistical analysis using commercial software (Excel 2007; Microsoft Corporation, Redmond, WA, USA) and GraphPad version 4 (GraphPad Software, Inc., La Jolla, CA, USA). Two-sample paired $t$-tests were used to compare the mean values of the continuous variables between study groups. In all data analyses, a $P$-value $<0.05$ was considered statistically significant.

\section{Results}

According to the presence and stage of ROP, group 1 (434 eyes) included 217 preterm infants without signs of ROP. Group 2 (56 eyes) included 28 preterm infants with 
Table I Summary statistics of the enrolled patients

\begin{tabular}{lllll}
\hline & Patients & Eyes & $\begin{array}{l}\text { Mean GA } \\
\text { (week } \pm \text { SD) }\end{array}$ & $\begin{array}{l}\text { Mean BW } \\
\text { (g } \pm \text { SD) }\end{array}$ \\
\hline Group I & 217 & 434 & $29.4 \pm 3 . \mathrm{I}$ & $\mathrm{I}, 345 \pm 34$ \\
Group 2 & 28 & 56 & $30.2 \pm 3.4$ & $\mathrm{I}, 291 \pm 89$ \\
Group 3 & 16 & 32 & $29.3 \pm \mathrm{I} . \mathrm{I}$ & $\mathrm{I}, 306 \pm 78$ \\
\hline
\end{tabular}

Notes: Group I: no ROP; Group 2: mild ROP; Group 3: severe ROP. Abbreviations: GA, gestational age; SD, standard deviation; BW, birth weight; ROP, retinopathy of prematurity.

mild ROP. Group 3 (32 eyes) included 16 preterm infants with severe ROP. The summary statistics of the included patients are reported in Table 1, which shows the mean GA and weight at birth in the three different groups. The refractive status and ocular alignment rates are shown in Figures 1 and 2.

In groups 1 and 2, the most represented refractive error at 1 year old was astigmatism ( $54 \%$ and $53 \%$, respectively), while at 6 years old it was hyperopia ( $62 \%$ and $48 \%$, respectively). In group 3, myopia was the most represented refractive error at 1 year old (41\%), and hyperopia was the most represented at 6 years old (41\%). Figure 2 showed the same rates, which were classified according to the refractive values. Significant anisometropia ( $\geq 1.5 \mathrm{D})$ was reported in three patients in group 1, two patients in group 2, and four patients in group 3 .

With regard to ocular alignment, the most frequent deviation in each group was esotropia, both at 1 year old (Group 1, 3.4\%; Group 2, 7.1\%; Group 3, 21\%) and at 6 years old (Group 1, 8.2\%; Group 2, 15\%; Group 3, 31.25\%).

Only two cases of nystagmus were observed in group 1; three cases of nystagmus were identified in group 3 .

\section{Discussion}

The most active stage of ocular development is known to be from 6 months in utero to term. ${ }^{5}$ While previous studies focus particularly on the development of myopia, in the present study, we have considered all refractive errors myopia, hyperopia, and astigmatism - together with the presence of strabismus at two different stages of infant growth.
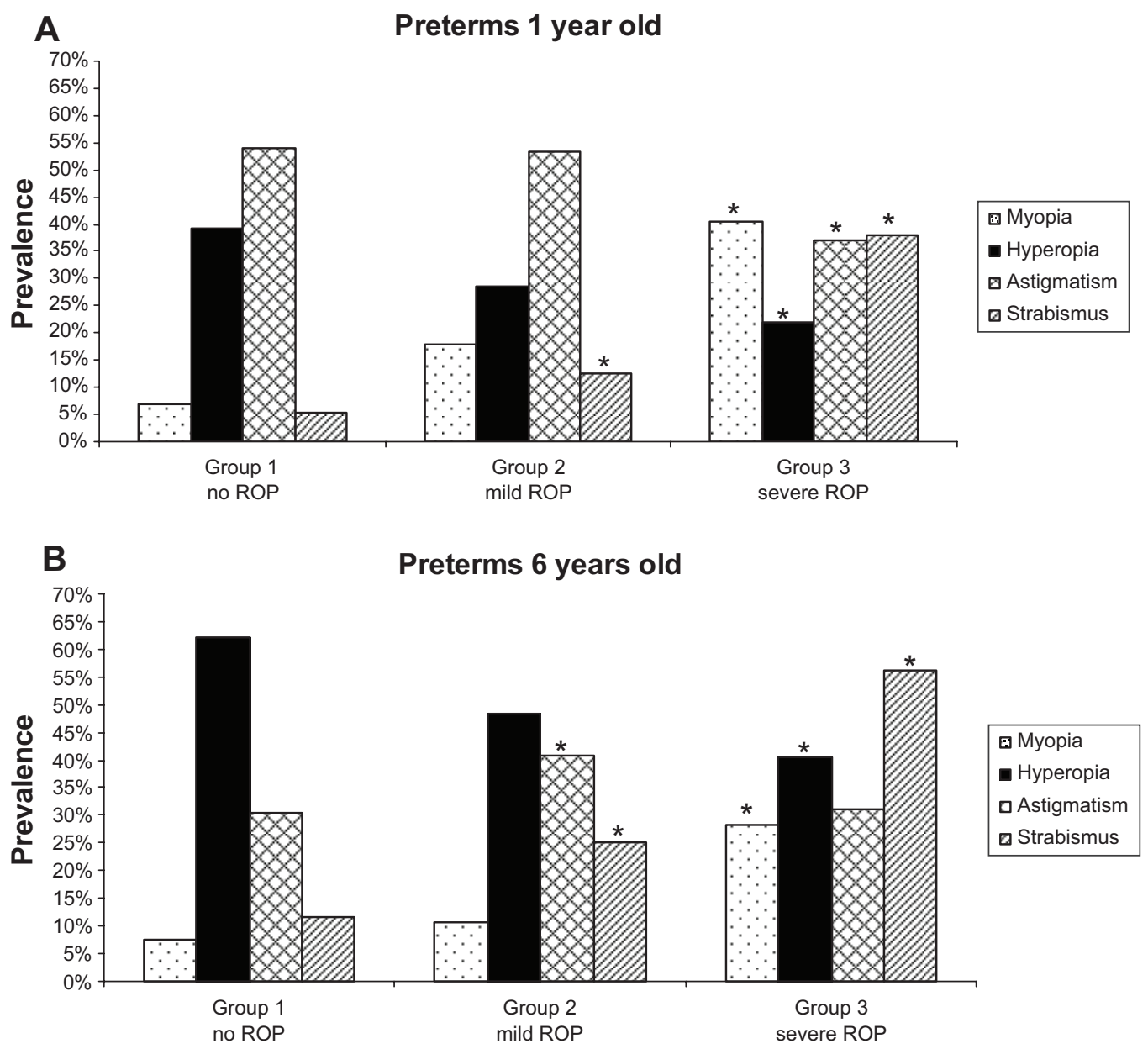

Figure I Refractive error prevalence at I year old and 6 years old in all groups.

Notes: (A) I year old; (B) 6 years old. $* P<0.05$ : statistically significant differences of groups 2 and 3 , respectively, versus group I.

Abbreviation: ROP, retinopathy of prematurity. 


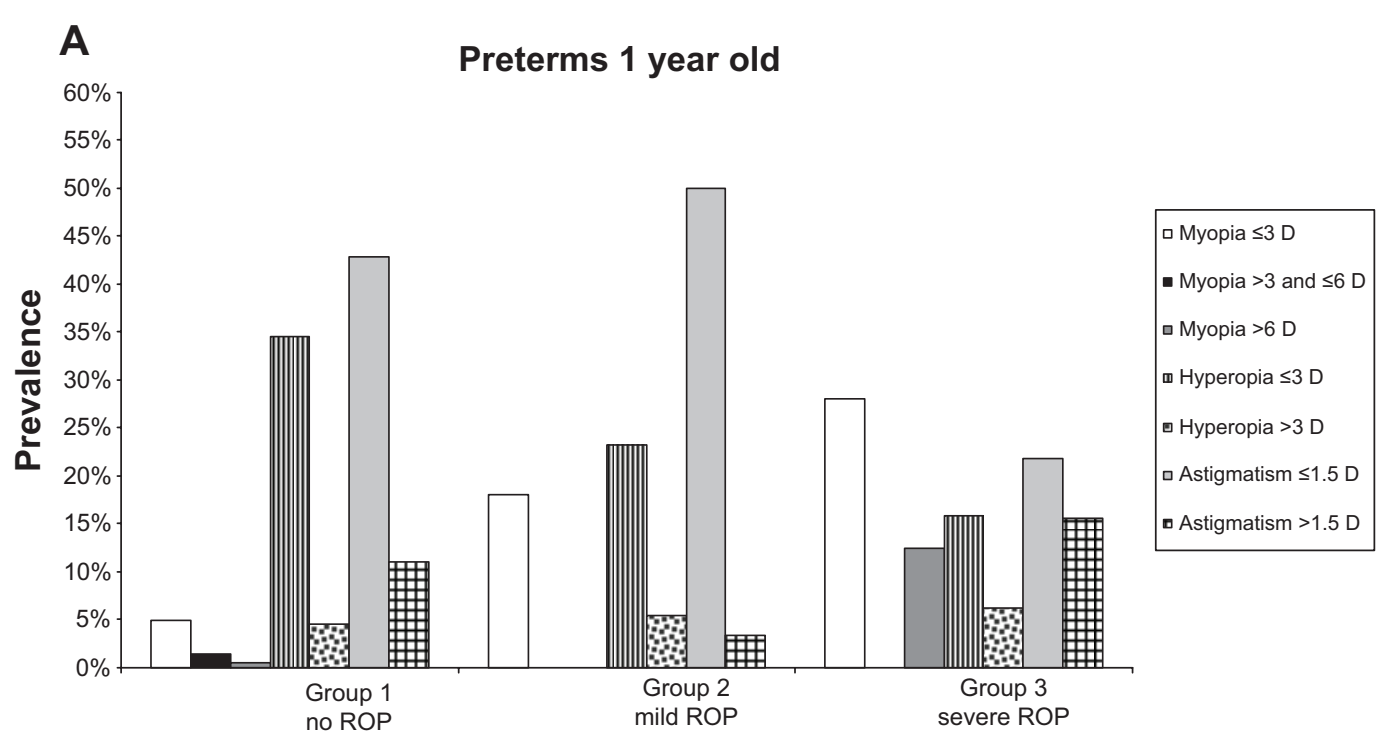

\section{B Preterms 6 years old}

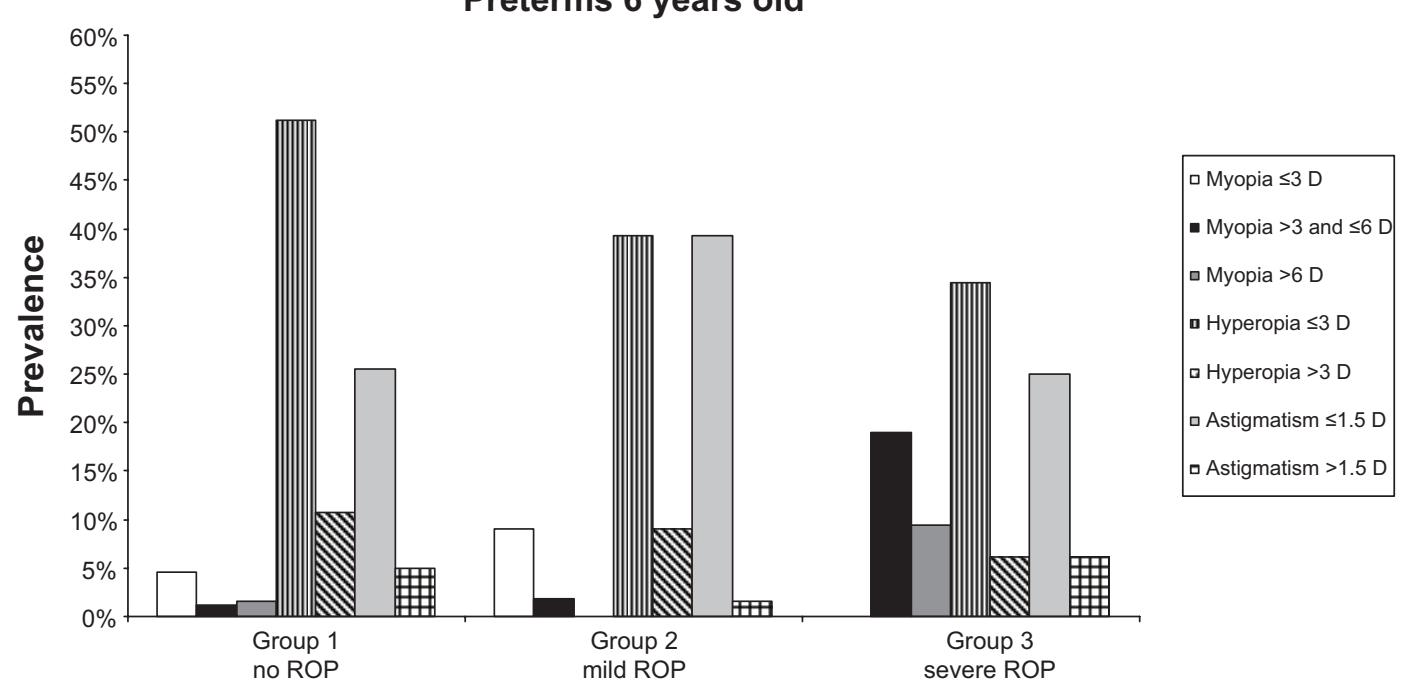

Figure 2 Refractive error prevalence at I year old and 6 years old in all groups. Note: Analysis of different classes according to refractive power (see figure legend). Abbreviation: ROP, retinopathy of prematurity.

Myopia is present in preterm infants, and its prevalence increases with the degree of prematurity and with ROP severity. ${ }^{18-20}$ Some authors have already described three types of myopia associated with prematurity. ${ }^{12,13}$ The first is physiological myopia, which is associated with premature birth and stage of gestation. It is secondary to a flat anterior chamber, increased corneal curvature, and a spherical lens. The second type is called MOP, which is the arrested development of the anterior segment, occurs irrespective of ROP. MOP is characterized by a short axial length, a shallow anterior chamber, and a thick lens. ${ }^{14,15}$ The third type of myopia is secondary to severe ROP. It can vary from mild to severe, and it is stable throughout childhood. In our study (Figures 1 and 2), the prevalence of myopia was significantly higher in preterm children with severe ROP, compared with those without ROP at 1 year old $(40.6 \%$ versus $7 \%$, respectively; $P<0.05)$ and 6 years old $(28 \%$ versus $7 \%$, respectively; $P<0.05$ ). Moreover, at 6 years old, in accordance with Garcia-Valenzuela and Kaufman in 2005, ${ }^{20}$ our study underlined incremental rates of myopia that were higher than $3 \mathrm{D}$ in patients with severe ROP compared with patients with mild or no ROP, probably due to a mechanism of altered anterior segment development (Figure 2).

It is known that infants at term are commonly hypermetropic, and this kind of refractive error is primarily axial. ${ }^{21}$ Figure 1 clearly shows the increased prevalence of hyperopia in each study group at 6 years old compared to the situation observed at 1 year old. O'Connor et $\mathrm{al}^{22}$ reported that $20.5 \%$ of preterm eyes become more hyperopic at age 10 years. In accordance with Haugen et $\mathrm{a}^{23}$ our study showed that 
hypermetropic refractive error was prevalent between $0 \mathrm{D}$ and $3 \mathrm{D}$ rather than $>3 \mathrm{D}$ at both visits (Figure 2). High hyperopia was found in only one child, who was affected by microphthalmia and severe ROP, which was treated with cryotherapy.

The prevalence of astigmatism, in accordance with Larsson and Holmström, ${ }^{24}$ decreased in all groups at 6 years old compared to the situation at 1 year old (Figure 1). Corneal curvature might be influenced by prematurity, and some studies have suggested that abnormally steep curvature disappears gradually during infancy. ${ }^{25}$ The presence of astigmatism might be caused by an arrest in the normal process of emmetropization. ${ }^{26}$ It is well known that preterm birth influences the process of emmetropization by arresting the development of the anterior segment (induced by temperature decreases during corneal growth), or by causing biological stress (retinopathy). ${ }^{7,27,28}$ In contrast with the evidence we observed with patients who were 6 years old, Theng et $\mathrm{al}^{29}$ found increasing degrees of astigmatism in premature infants during the first 3 years. Our study concluded that the presence of astigmatism at 1 year old is not predictive of further development of this defect during a child's development (Figures 1 and 2).

The high incidence of strabismus in preterm children has an unclear pattern of development and etiology, which has implications for its management. Strabismus may be attributed to ROP, increased refractive errors, anisometropia, BW, and neurological impairment. ${ }^{30,31}$ Shah et al ${ }^{32}$ described occipital brain volume reduction in preterm children affected by strabismus. Schalij-Delfos et $\mathrm{al}^{33}$ found that the rate of strabismus increases with decreasing GA. The incidence of strabismus in our study (Figure 1) was significantly higher in preterm children with mild and severe ROP $(P<0.05)$ when compared to children without ROP at 1 year and 6 years of age. Moreover, manifest strabismus was associated with hyperopia (esotropia), and in many cases with myopia (exotropia), but further investigation in this area is needed. Many authors have found that the onset of strabismus in preterm infants is variable, which influences the planning of long-term follow-up and care. ${ }^{34,35}$

We found that nine out of 217 preterm children $(1.6 \%)$ were affected by anisometropia. In accordance with other authors, we noted a low prevalence of anisometropia in ROP patients ( eyes and it doesn't represent a risk factor for a different ocular development might be influenced in the same way. ${ }^{36,37}$

This study presented some limits. 1) The number of patients included in groups 2 and 3 presenting with different stages of ROP is limited, as the treatment of preterm children nowadays has changed and severe stages of ROP are rare.
2) Astigmatism was evaluated using retinoscopy rather than keratometry. This modality was necessary in order to make this evaluation possible in infants, as keratometry requires good patient/physician collaboration; moreover, a cycloplegic autorefraction/autokeratometry was not available. 3) Many authors have previously studied the relationship between refractive errors and premature birth: some differences in the prevalence rates of myopia, hyperopia, astigmatism, and anisometropia can be largely attributed to the different BW and GA criteria used to define a preterm infant. $8,11,16,38$

\section{Conclusion}

Refractive errors and strabismus are common in preterm children. We observed increasing rates of both hyperopia and strabismus in all preterm children at 1 year and 6 years old, and these findings might be considered as refractive sequelae of preterm birth. Our study shows that the rate of astigmatism measured via retinoscopy might be a marker of eye immaturity in all preterm children. As per the findings in the literature, decreased prevalence of astigmatism at 6 years old might explain the progressive development and modification of anterior segment structures (mostly corneal curvature). The prevalence of myopia and strabismus in preterm children with ROP is significantly higher $(P<0.05)$ than in those without ROP, and the risk of these disorders increases significantly $(P<0.05)$ with the severity of ROP.

These disorders must all be recognized early in preterm children. Particularly in patients with ROP, early and longterm follow up is important for correct lens prescription to avoid severe amblyopia in adulthood. Moreover, in our study, we found that the presence of astigmatism at 1 year old is not predictive of the further development of this defect during child growth. The importance of ophthalmological visits in childhood should be emphasized. Further studies are needed to examine refractive error changes in preterm patients during adolescence up to adulthood.

\section{Acknowledgment}

The authors thank Michael John (BA) of the San Raffaele Medical School for the English language editing of this manuscript.

\section{Disclosure}

The authors report no conflicts of interest in this work.

\section{References}

1. Chen C, Zhang QS. [Advances in medical care for extremely low birth weight infants worldwide]. Zhongguo Dang Dai Er Ke Za Zhi. 2013;15(8):703-707. Chinese.

2. Mccolm JR, Fleck BW. Retinopathy of prematurity: causation. Semin Neonatol. 2001;6(6):453-460. 
3. Gogate P, Gilbert C, Zin A. Severe visual impairment and blindness in infants: causes and opportunities for control. Middle East Afr J Ophthalmol. 2011;18(2):109-114.

4. Gilbert C, Fielder A, Gordillo L, et al; International NO-ROP Group. Characteristics of infants with severe retinopathy of prematurity in countries with low, moderate, and high levels of development: implications for screening programs. Pediatrics. 2005;115(5):e518-e525.

5. Hellström A, Smith LE, Dammann O. Retinopathy of prematurity. Lancet. 2013;382(9902):1445-1457.

6. Chen J, Stahl A, Hellstrom A, Smith LE. Current update on retinopathy of prematurity: screening and treatment. Curr Opin Pediatr. 2011; 23(2):173-178.

7. Ibarra MS, Capone A. Retinopathy of prematurity and anterior segment complications. Ophthalmol Clin North Am. 2004;17(4):577-582, vii.

8. Goktas A, Sener EC, Sanac AS. An assessment of ocular morbidities of children born prematurely in early childhood. J Pediatr Ophthalmol Strabismus. 2012;49(4):236-241.

9. O'Connor AR, Wilson CM, Fielder AR. Ophthalmological problems associated with preterm birth. Eye (Lond). 2007;21(10):1254-1260.

10. Wang J, Ren X, Shen L, Yanni SE, Leffler JN, Birch EE. Development of refractive error in individual children with regressed retinopathy of prematurity. Invest Ophthalmol Vis Sci. 2013;54(9):6018-6024.

11. Chen TC, Tsai TH, Shih YF, et al. Long-term evaluation of refractive status and optical components in eyes of children born prematurely. Invest Ophthalmol Vis Sci. 2010;51(12):6140-6148.

12. Quinn GE, Dobson V, Davitt BV, et al; Early Treatment for Retinopathy of Prematurity Cooperative Group. Progression of myopia and high myopia in the Early Treatment for Retinopathy of Prematurity study: findings at 4 to 6 years of age. J AAPOS. 2013;17(2):124-128.

13. Nissenkorn I, Yassur Y, Mashkowski D, Sherf I, Ben-Sira I. Myopia in premature babies with and without retinopathy of prematurity. $\mathrm{Br} \mathrm{J}$ Ophthalmol. 1983;67(3):170-173.

14. Fielder AR, Quinn GE. Myopia of prematurity: nature, nurture, or disease? Br J Ophthalmol. 1997;81(1):2-3.

15. Fledelius HC. Preterm delivery and subsequent ocular development. A 7-10 year follow-up of children screened 1982-84 for ROP. 3) Refraction. Myopia of prematurity. Acta Ophthalmol Scand. 1996;74(3): 297-300.

16. Choi RY, Kushner BJ. The accuracy of experienced strabismologists using the Hirschberg and Krimsky tests. Ophthalmology. 1998;105(7):1301-1306.

17. Schmid M, Largo RH. Visual acuity and stereopsis between the ages of 5 and 10 years. A cross-sectional study. Eur J Pediatr. 1986;145(6):475-479.

18. Quinn GE, Dobson V, Kivlin J, et al. Prevalence of myopia between 3 months and $51 / 2$ years in preterm infants with and without retinopathy of prematurity. Cryotherapy for Retinopathy of Prematurity Cooperative Group. Ophthalmology. 1998;105(7):1292-1300.

19. Gallo JE, Fagerholm P. Low-grade myopia in children with regressed retinopathy of prematurity. Acta Ophthalmol (Copenh). 1993;71(4): 519-523.

20. Garcia-Valenzuela E, Kaufman LM. High myopia associated with retinopathy of prematurity is primarily lenticular. J AAPOS. 2005;9(2): $121-128$.

21. Denis D, Benso C, Wary P, Fogliarini C. Childhood refraction: epidemiology, progression, evaluation and a method for correcting ametropia. J Fr Ophtalmol. 2004;27:943-952.

Clinical Ophthalmology

\section{Publish your work in this journal}

Clinical Ophthalmology is an international, peer-reviewed journal covering all subspecialties within ophthalmology. Key topics include: Optometry; Visual science; Pharmacology and drug therapy in eye diseases; Basic Sciences; Primary and Secondary eye care; Patient Safety and Quality of Care Improvements. This journal is indexed on Submit your manuscript here: http://www.dovepress.com/clinical-ophthalmology-journal
22. O'Connor AR, Stephenson TJ, Johnson A, Tobin MJ, Ratib S, Fielder AR. Strabismus in children of birth weight less than 1701 g. Arch Ophthalmol. 2002;120(6):767-773.

23. Haugen OH, Nepstad L, Standal OA, Elgen I, Markestad T. Visual function in 6 to 7 year-old children born extremely preterm: a populationbased study. Acta Ophthalmol. 2012;90(5):422-427.

24. Larsson EK, Holmström GE. Development of astigmatism and anisometropia in preterm children during the first 10 years of life: a population-based study. Arch Ophthalmol. 2006;124(11): 1608-1614.

25. Friling R, Weinberger D, Kremer I, Avisar R, Sirota L, Snir M. Keratometry measurements in preterm and full term newborn infants. Br J Ophthalmol. 2004;88(1):8-10.

26. Choi MY, Park IK, Yu YS. Long-term refractive outcome in eyes of preterm infants with and without retinopathy of prematurity: comparison of keratometric value, axial length, anterior chamber depth, and lens thickness. Br J Ophthalmol. 2000;84(2):138-143.

27. Kent D, Pennie F, Laws D, White S, Clark D. The influence of retinopathy of prematurity on ocular growth. Eye (Lond). 2000;14(Pt 1):23-29.

28. Fledelius HC, Jensen $\mathrm{H}$. Late subsequent ocular morbidity in retinopathy of prematurity patients, with emphasis on visual loss caused by insidious 'involutive' pathology: an observational series. Acta Ophthalmol. 2011;89(4):316-323.

29. Theng JT, Wong TY, Ling Y. Refractive errors and strabismus in premature Asian infants with and without retinopathy of prematurity. Singapore Med J. 2000;41(8):393-397.

30. Larsson EK, Rydberg AC, Holmström GE. A population-based study of the refractive outcome in 10-year-old preterm and full-term children. Arch Ophthalmol. 2003;121(10):1430-1436.

31. Bremer DL, Palmer EA, Fellows RR, et al. Strabismus in premature infants in the first year of life. Cryotherapy for Retinopathy of Prematurity Cooperative Group. Arch Ophthalmol. 1998;116(3):329-333.

32. Shah DK, Guinane C, August P, et al. Reduced occipital regional volumes at term predict impaired visual function in early childhood in very low birth weight infants. Invest Ophthalmol Vis Sci. 2006; 47(8):3366-3373.

33. Schalij-Delfos NE, de Graaf ME, Treffers WF, Engel J, Cats BP. Longterm follow up of premature infants: detection of strabismus, amblyopia, and refractive errors. Br J Ophthalmol. 2000;84(9):963-967.

34. Kushner BJ. Strabismus and amblyopia associated with regressed retinopathy of prematurity. Arch Ophthalmol. 1982;100(2):256-261.

35. Holmström G, el Azazi M, Kugelberg U. Ophthalmological follow up of preterm infants: a population based, prospective study of visual acuity and strabismus. Br J Ophthalmol. 1999;83(2):143-150.

36. Cooke RW, Foulder-Hughes L, Newsham D, Clarke D. Ophthalmic impairment at 7 years of age in children born very preterm. Arch Dis Child Fetal Neonatal Ed. 2004;89(3):F249-F253.

37. Darlow BA, Clemett RS, Horwood LJ, Mogridge N. Prospective study of New Zealand infants with birth weight less than $1500 \mathrm{~g}$ and screened for retinopathy of prematurity: visual outcome at age 7-8 years. Br J Ophthalmol. 1997;81(11):935-940.

38. Yang CS, Wang AG, Sung CS, Hsu WM, Lee FL, Lee SM. Long-term visual outcomes of laser-treated threshold retinopathy of prematurity: a study of refractive status at 7 years. Eye (Lond). 2010;24(1):14-20.

\section{Dovepress}

PubMed Central and CAS, and is the official journal of The Society of Clinical Ophthalmology (SCO). The manuscript management system is completely online and includes a very quick and fair peer-review system, which is all easy to use. Visit http://www.dovepress.com/ testimonials.php to read real quotes from published authors. 